\title{
DISTILLATION PROFILES IN TERNARY HETEROGENEOUS MIXTURES WITH DISTILLATION BOUNDARIES: STAGED COLUMNS
}

\author{
Andrzej Ryszard Królikowski* \\ Wrocław University of Technology, Chemical Engineering Institute, \\ ul. C.K. Norwida 4/6, 50-373 Wrocław, Poland
}

\begin{abstract}
Distillation boundaries originate from saddle azeotropes, dividing the composition space into distillation regions. In heterogeneous mixtures distilled in packed columns, distillation regions overlap. The common area of distillation regions is parametrically sensitive, and it determines the possibilities of crossing (at a finite reflux) the distillation boundaries defined for a total reflux or reboil ratio. This work is an extended research of the paper (Królikowski et al., 2011) conducted to scrutinize whether the distillation regions overlapped in heteroazeotropic systems distilled in staged columns. Presented studies were performed by finding such composition points of the products, for which the rectifying profiles of staged columns were ended in different distillation regions. Calculations were executed for the heterogeneous mixture classified under Serafimov's topological class as 3.1-2: ethanol - benzene - water. Distillation regions for staged columns were found to overlap each other in the heterogeneous systems. As a result, their common part was parametrically sensitive.
\end{abstract}

Keywords: distillation, distillation profiles, distillation boundaries, staged column, heterogeneous mixtures

\section{INTRODUCTION}

Separation has always been an important task in the chemical industry. Continuous distillation processes are commonly used in industry practice for the separation of azeotropic mixtures. Such processes can be intricate to design and require new design methods. Moreover, the design process of the distillation systems for the separation of non-ideal mixtures with mutual immiscible liquid regions and many distillation regions is a complex issue. Examining separability and selecting feasible processing conditions by the extensive simulation studies is tedious and very time-consuming, despite the application of modern computational techniques. Owing to that, only a small selection of promising process alternatives is analyzed at a time, whereas other potentially attractive alternatives are dismissed. In this trial-and-error technique, all the input variables and processing parameters are specified (usually estimated by guessing, extrapolation of existing separation systems or by applying short-cut methods), and the composition and flows of the products are calculated. On the other hand, designing method through simulation is a robust technique for ascertaining the performance of existing columns.

Despite that numerous researchers made attempts to develop techniques and methods for the assessment of the feasibility studies for azeotropic mixtures (e.g.: Baur et al., 2005; Bossen et al., 1993; Castillo and Towler, 1998; Doherty and Caldarola, 1985; Fidkowski et al., 1993; Jobson et al., 1995; Levy et al., 1985; Mortaheb and Kosuge, 2004; Petlyuk et al., 1965; Rév, 1992; Safrit and Westerberg, 
1997; Springer et al., 2002; Taylor et al., 2004; Teixeira et al., 2009; Van Dongen and Doherty, 1984), a complete solution for ternary mixtures with distillation boundaries has not yet been found. In addition, despite many efforts on reflection on distillation boundaries made by above-mentioned researchers, the nature of distillation boundaries had been still not precisely known until the paper published by Królikowski (2006). The author considered the determination of all three known types of distillation boundaries. He also used a bifurcation theory and tracked all pinch points of rectifying and stripping profiles then mapped the branches of solutions and checked whether composition profiles jumped at bifurcation points.

As it is very well known, especially when dealing with the simulation and design of distillation columns and processes, it is essential to know the limitations defined by the vapor(-liquid)-liquid equilibrium of the system under consideration. The key synthesis concept for distillation design focuses on understanding the fundamentals in which azeotropes (or other constant boiling mixtures) define separation boundaries. It is now well found that azeotropes often define curved distillation boundaries that place limitations on the degree of separation that can be achieved. In this situation, only those design methods are useful, that analyze and examine the whole composition space, azeotropes, residue curve separatrices, distillation line separatrices, pinch point curves, composition profiles and distillation boundaries. An analysis of the distillation boundary trajectories allows identifying which products are obtainable. When combined with geometrical methods, the analysis facilitates, simplifies and speeds up the distillation column design process saving valuable time and resources. With these methods, infeasible designs can be revealed out quickly at the early stage of the design process. Despite this, there remains no clear, exact and absolute understanding of the influence of distillation boundaries on the physical properties of distilled system, and straightforward way of accurately analyzing them in practice.

Presented manuscript clarifies how the existence of distillation boundaries (and hence distillation regions) influences the behavior of distillation profiles of staged distillation columns. This paper is a part of a larger tool for examination of properties of distillation boundaries in nonideal mixtures. The ultimate aim of the work is a toolbox for distillation feasibility studies which combines geometrical methods with analysis of all possible singular points, trajectories and separatrices in the whole composition space of a mixture.

Detailed description of distillation boundaries can be found in: Brüggemann and Marquardt (2011a, b); Królikowski et al. (2007, 2011); Królikowski (2001, 2006); Lucia and Taylor (2006, 2007). To remind the reader - distillation boundaries are created by saddle azeotropes and divide the composition space into distillation regions. There are distinguished three types of distillation boundaries: simple distillation boundary $(S D B)$, total reflux boundary $(T R B)$ and pitchfork distillation boundary $(P D B)$. A different pair of distillation boundaries is referred to staged and packed columns - TRB \& PDB and $S D B \& P D B$, respectively (Jobson et al., 1995; Królikowski, 1999, 2002). It was assumed that relative location of distillation boundaries is the same as that set up by Kiva et al. (2003). Thus, for stable separatrices, the $S D B$ lies between the TRB and the $P D B$, and it may be crossed from each side by stripping profiles of staged column. In the case of unstable separatrices, the TRB is located between the $S D B$ and the $P D B$ and it is obvious that it may be crossed from each side by rectifying profiles of packed column. As a result, the common part of distillation regions, which is enclosed between the pair of matching distillation boundaries, is parametrically sensitive (homogeneous mixtures Królikowski, 2003; heterogeneous mixtures - Królikowski et al., 2011).

\section{OVERLAPPING OF DISTILLATION REGIONS: STAGED COLUMNS}

With the aim of confirming that distillation regions overlap in heterogeneous mixtures distilled in packed column, such composition points of products (located between the corresponding pair of 
distillation boundaries) have to be found, that composition profiles will end in the different distillation regions for. The behavior of composition profile as well as the assignment of the pinch point of given concentration profile to a specific distillation region depends either on the reflux value or on the reboil ratio. The critical values of the reflux or reboil ratio can be determined throughout a parametric studies (e.g. Wahnschafft et al., 1992).

Studies were performed for mixture classified under Serafimov's topological class (Serafimov, 1970) as 3.1-2: ethanol - benzene - water, since calculations and simulations made for other heterogeneous three-component mixtures (e.g. benzene - tert-butanol - water, ethanol - water - toluene or benzene water - formic acid) showed the same behaviours and properties as mixture researched in this paper. All of the distillation boundaries $(S D B \mathrm{~s}$ and $T R B \mathrm{~s})$ in the examined mixture are unstable separatrices and link the saddle point with the unstable node. Thus, there is total reflux boundary on the convex side of simple distillation boundary, with pitchfork distillation boundary located farther on.

\subsection{Calculation model}

Here was only discussed continuous distillation process performed in staged column, since the situation for the packed column with simple distillation boundary was similar (Królikowski et al., 2011). The model used in calculations was simplified by assuming constant molar flows in the column's sections. Temperatures on all stages were obtained by bubble point calculations at constant atmospheric pressure $p=1 \mathrm{~atm}$. Perfect mixing and equilibrium in all stages were assumed. To calculate vapor-liquid-liquid equilibrium of ethanol - benzene - water mixture studied herein, the set of binary interaction parameters for the NRTL activity coefficient model (Renon and Prausnitz, 1968, 1969), and the constants used to calculate standard state fugacities were required. The standard component fugacities for ideal vapor phase were formed using ideal gas model with Antoine equation (Antoine, 1888) in the form:

$$
f^{0}=\exp \left(A-\frac{B}{C+X}\right)
$$

where $f^{0}$ has units of mmHg while $X$ is in ${ }^{\circ} \mathrm{C}$. All of the relevant numerical values of the pure component constants in the Eq. (1) as well as literature references are provided in Table 1. The activity coefficients for the liquid phase were modeled by the NRTL equation with parameters $\tau_{i j}$ and $\tau_{j i}$ as well as $G_{i j}$ and $G_{j i}$ expressed in the form:

$$
\tau_{i j}=\exp \left(\frac{A_{i j}}{R T}+B_{i j}\right) \text { and } \tau_{j i}=\exp \left(\frac{A_{j i}}{R T}+B_{j i}\right)
$$

and

$$
G_{i j}=\exp \left(\alpha_{i j} \tau_{i j}\right) \text { and } G_{j i}=\exp \left(\alpha_{j i} \tau_{j i}\right)
$$

In this study, all $B_{i j}$ and $B_{j i}$ values were set to zero. Table 2 supplies the binary interaction parameters for the chemical species used herein with relevant literature references.

The resulting mathematical model took the form of the set of differential and algebraic equations (DAE system) and was solved in Matlab® 2010a programming environment (The Math Works, Inc.) with the DAE solver ODE15s (Shampine and Reichelt, 1997). Rectification profiles for staged columns were determined using the Distil 6.2 (afterwards Conceptual Engineering) software from AspenTech, Inc., with the following assumptions: distillation column used in simulations was one-feed column with theoretical stages, equipped with total condenser (zero stage) and had not got a decanter on top; column was equipped with evaporator (last stage); distillate and reflux streams were diphase. None of reflux policies was included. The distillate composition was not split into a product rich phase and an entrainer rich phase, so it can be called a pseudo-homogeneous. 
Table 1. Pure component constants for the Antoine equation

\begin{tabular}{|c|c|c|c|c|c|}
\hline Component & $A$ & $B$ & $C$ & $\begin{array}{c}\text { Temperature range } \\
{\left[{ }^{\circ} \mathrm{C}\right]}\end{array}$ & Literature references \\
\hline Ethanol & 8.11220 & 1592.864 & 226.184 & $20-93$ & Gmehling et al., 1977 \\
\hline Benzene & 6.87987 & 1196.760 & 219.161 & $8-80$ & Gmehling et al., 1977 \\
\hline Water & 8.07131 & 1730.630 & 233.426 & $1-100$ & Gmehling et al., 1977 \\
\hline
\end{tabular}

Table 2. Binary interaction parameters for the NRTL model. Appropriate conversion to SI units is $1 \mathrm{cal} / \mathrm{mol}=4184.275 \mathrm{~J} / \mathrm{kg} \mathrm{mol}$

\begin{tabular}{|c|c|c|c|c|c|}
\hline Component $i$ & Component $j$ & $A_{i j}[\mathrm{cal} / \mathrm{mol}]$ & $A_{j i}[\mathrm{cal} / \mathrm{mol}]$ & $\alpha_{i j}=\alpha_{j i}$ & Literature references \\
\hline Ethanol & Benzene & 775.7625 & 1118.9759 & 0.6268 & Gmehling et al., 1977 \\
\hline Ethanol & Water & -109.6339 & 1332.3134 & 0.3031 & Gmehling et al., 1977 \\
\hline Benzene & Water & 1522.2402 & 1821.8322 & 0.3547 & $\begin{array}{c}\text { Distil 6.2 } \\
\text { internal database }\end{array}$ \\
\hline
\end{tabular}

After the use of another thermodynamic model (e.g. UNIQUAC) instead of NRTL, we can possibly get other composition points of azeotropes. Therefore, it is very important to choose an appropriate model to describe the phase equilibrium with proper effort and care. However, it does not really have actually so much significance, since the existence of distillation boundaries (and therefore distillation regions) and its properties is a physical property of the system (mixture), not of the thermodynamic model. Moreover, we can use values of azeotropic points determined experimentally or already available in the literature (e.g. Gmehling et al., 2004). Additionally, we can use another technique for determining distillation boundaries - e.g. geometric methodology presented by Lucia and Taylor (2006, 2007), where authors defined exact separation boundaries through the use of differential geometry and dynamical systems theory and formulated as a constrained global optimization problem (separation boundaries corresponded to local maxima in the line integral within a given separation region). Their methodology is very general and readily extends to other processes such as reactive separations, crystallization and vapor degreasing. In all cases, simulations will lead to practically the same results.

\subsection{Ethanol - benzene - water mixture}

Ethanol benzene - water solution forms a mixture that, at $p=1 \mathrm{~atm}$. exhibits two binary homoazeotropes: water - ethanol and ethanol - benzene, one binary heteroazeotrope benzene - water, as well as ternary heteroazeotrope that is the only one unstable node [un] with respect to Eq. (4) - the $n-1$ system of ordinary differential equations describing a simple distillation process of a $n$-component mixture:

$$
\frac{d x}{d \xi}=x-y(x)
$$

The ternary azeotrope in this system is the lowest boiling mixture. All three binary azeotropes are saddle nodes [sa], whereas the pure component vertices are stable nodes [sn] with respect to Eq. (4). All distillation boundaries in the mixture are unstable separatrices and run from each of the binary azeotropes, and end at ternary heteroazeotrope node (except one pitchfork distillation boundary, Fig. 1). They divide the composition space into distillation regions. As mentioned above - distillation boundaries are dependent on the applied equipment. Thus, a different pair of distillation boundaries is referred to the packed distillation column and the other one to the staged column (Fig. 2). In Fig. 2 there are shown common areas of distillation regions created by corresponding distillation boundaries. 
$P D B$ II and $P D B$ III have been distorted for the purpose of clarity (in fact, they are close to $T R B$ II/SDB II and TRB III/SDB III, respectively).

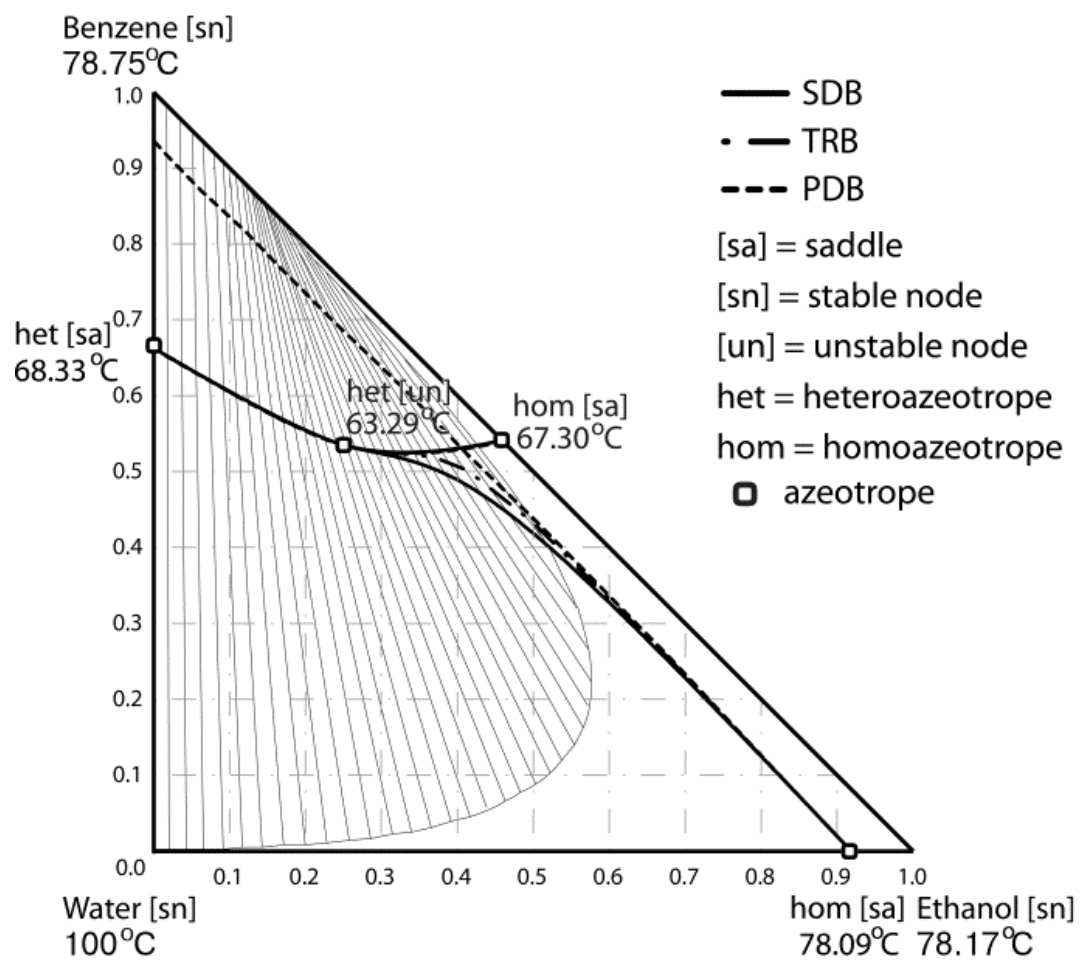

Fig. 1. Topology map and distillation boundaries for ternary heteroazeotropic mixture: ethanol - benzene - water

(a) Benzene [sn]

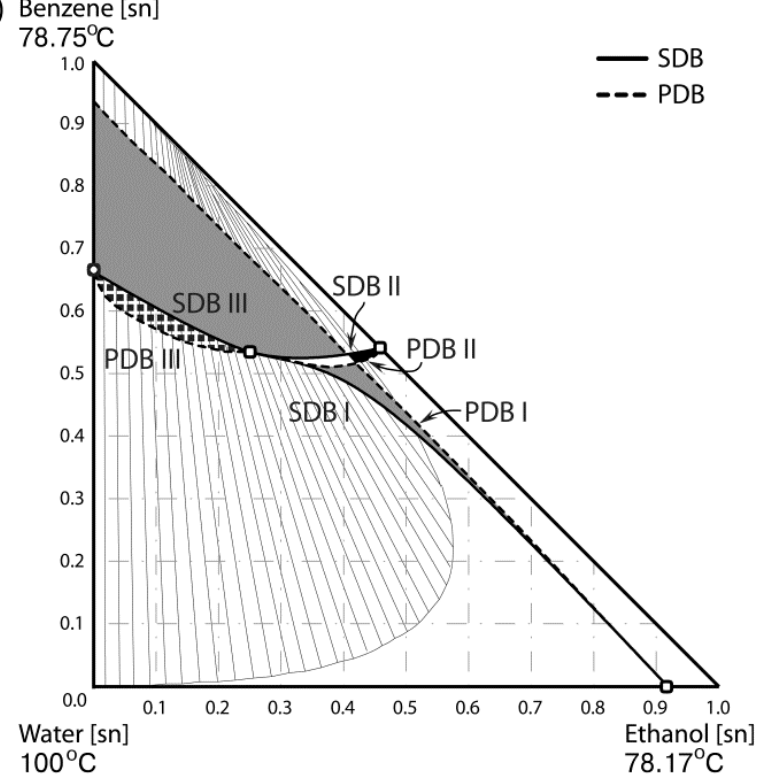

(b) Benzene [sn]

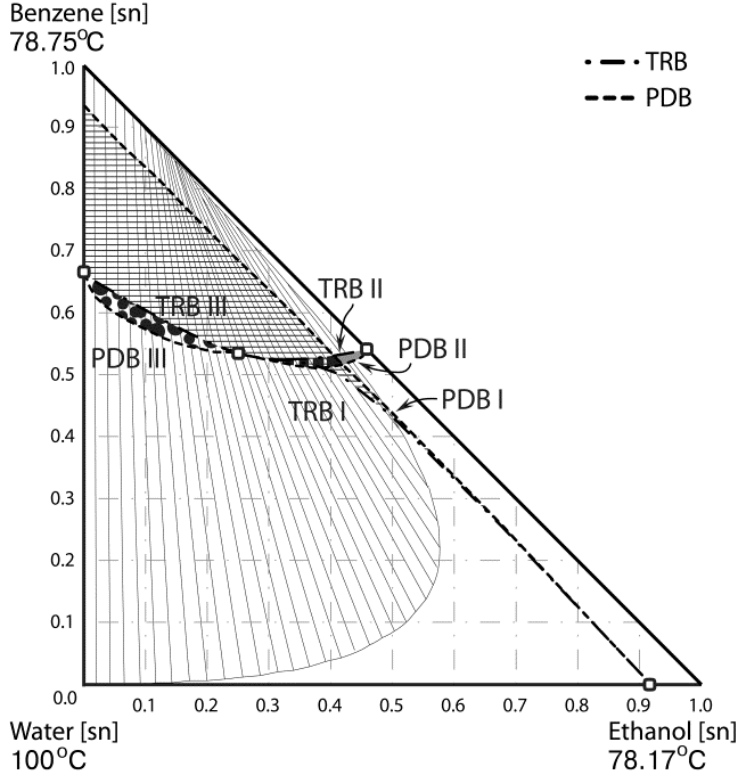

Fig. 2. Interaction of distillation boundaries (figure was distorted); (a) packed column and (b) staged column

For the staged column, total reflux boundary and pitchfork distillation boundary that originate from the same saddle azeotrope mark out two distillation regions, which overlap. One of the regions is located on the concave side of the $P D B$ and the last one on the convex side of the TRB. The area between the $T R B$ and the $P D B$ is the common part of the two regions. As a result, for the heterogeneous mixture studied herein, there are three regions responsible for the jump of rectifying profiles. One of them 
extends between $T R B$ I and $P D B$ I, the second one broadens between $T R B$ II and $P D B$ II and the last is determined by $T R B$ III and $P D B$ III.

A rectifying profile may jump only if the product composition lies between two appropriate distillation boundaries. For the heterogeneous distillate $\boldsymbol{z}_{\mathrm{D}}=(0.4719,0.4542,0.0739)$ located between the convex side of TRB I and the concave side of $P D B$ I, the rectification profile for the reflux ratio $R=42.9$ ran towards the stable water node, while the rectification profile for the reflux ratio $R=43.0$ rectification profile closed to the stable ethanol node (Fig. 3). Therefore, the distillate composition point was located in the parametrically sensitive area - common part of two distillation regions.

(a) Benzene

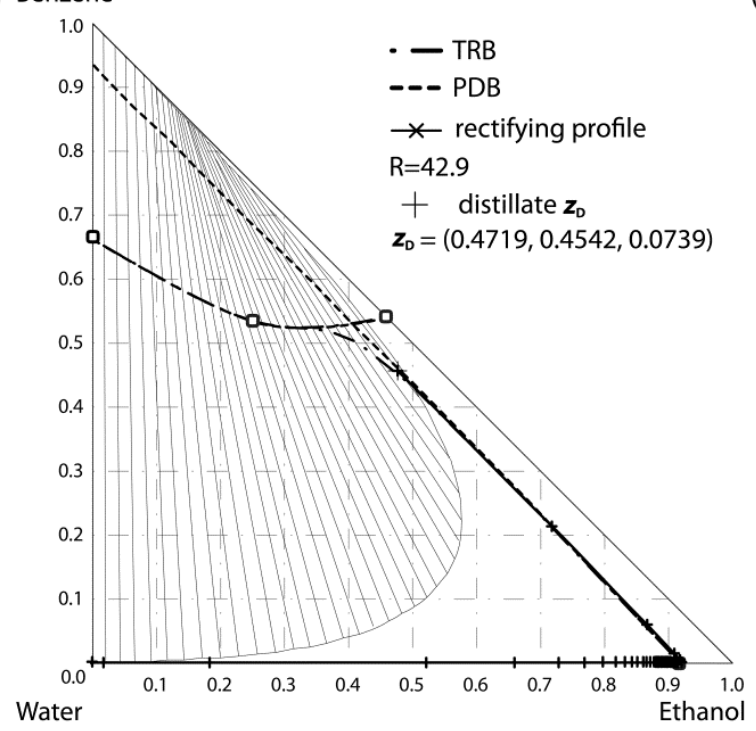

(b) Benzene

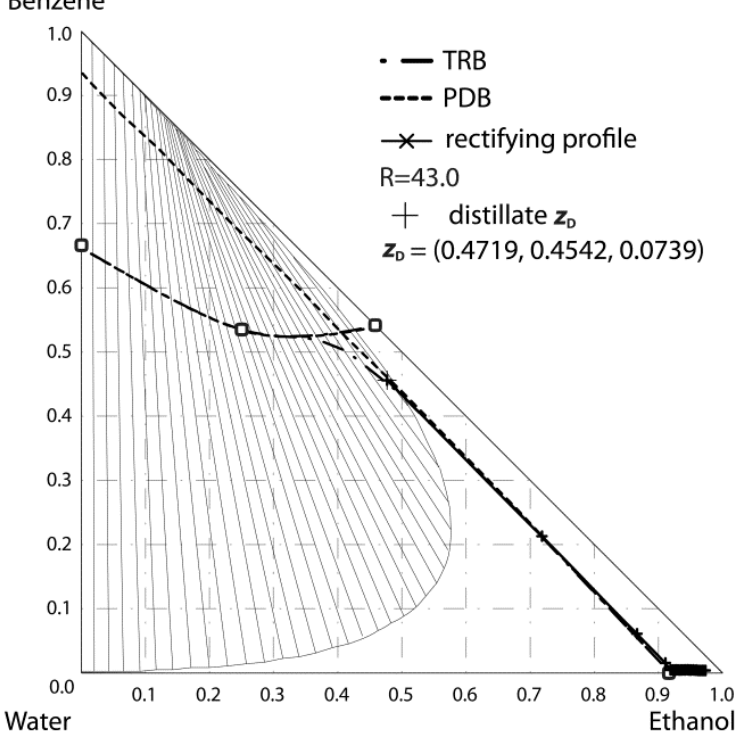

Fig. 3. Rectifying profiles for the distillate point placed on the distillation region determined by TRB I \& $P D B$ I.

(a) $R=42.9$ and (b) $R=43$

(a) Benzene

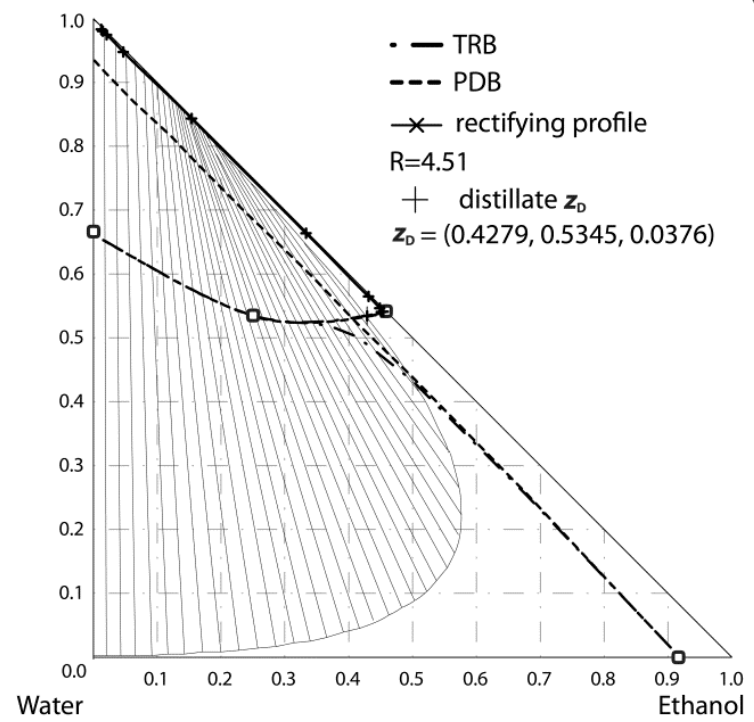

(b) Benzene

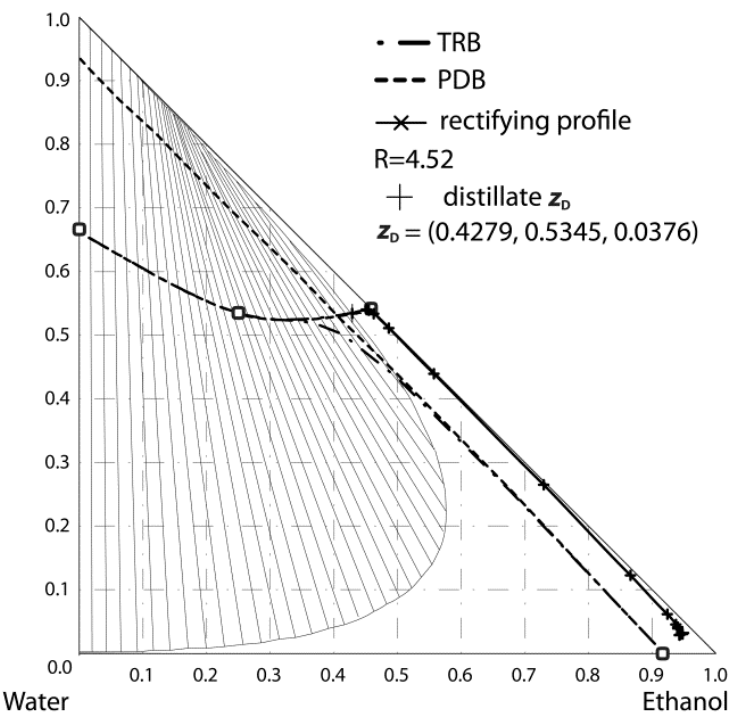

Fig. 4. Rectifying profiles for the distillate point placed on the distillation region determined by $T R B$ II \& PDB II. (a) $R=4.51$ and (b) $R=4.52$ 
Similar situation existed for the heterogeneous distillate $\boldsymbol{z}_{\mathrm{D}}=(0.4279,0.5345,0.0376)$ which was situated between total reflux boundary - TRB II and pitchfork distillation boundary - PDB II, which links the homogeneous saddle azeotrope ethanol - benzene with the ternary unstable heteroazeotrope. In this case, rectification profile for the reflux ratio $R=4.51$ ran in the direction of the stable benzene vertex, while after changing the reflux ratio to $R=4.52$ rectifying composition profile approached the stable ethanol node (Fig. 4). Therefore, also this product point was located in the common area of two distillation regions.

In some cases, regions between different total reflux boundaries and pitchfork distillation boundaries overlapped. They interacted in two possible ways. The first type of interaction occurred in the common area of two regions between certain TRBs and $P D B \mathrm{~s}$. The common space was bounded by TRB I, $P D B$ I, TRB II and $P D B$ II (Fig. 5). Thus for the heterogeneous distillate $z_{\mathbf{D}}=(0.3355,0.5231,0.1414)$ located in this confined area, for various values of the reflux ratio, rectifying profile might have ended in three different distillation regions, and ran towards stable nodes represented by pure components vertices in the composition space (Fig. 6).

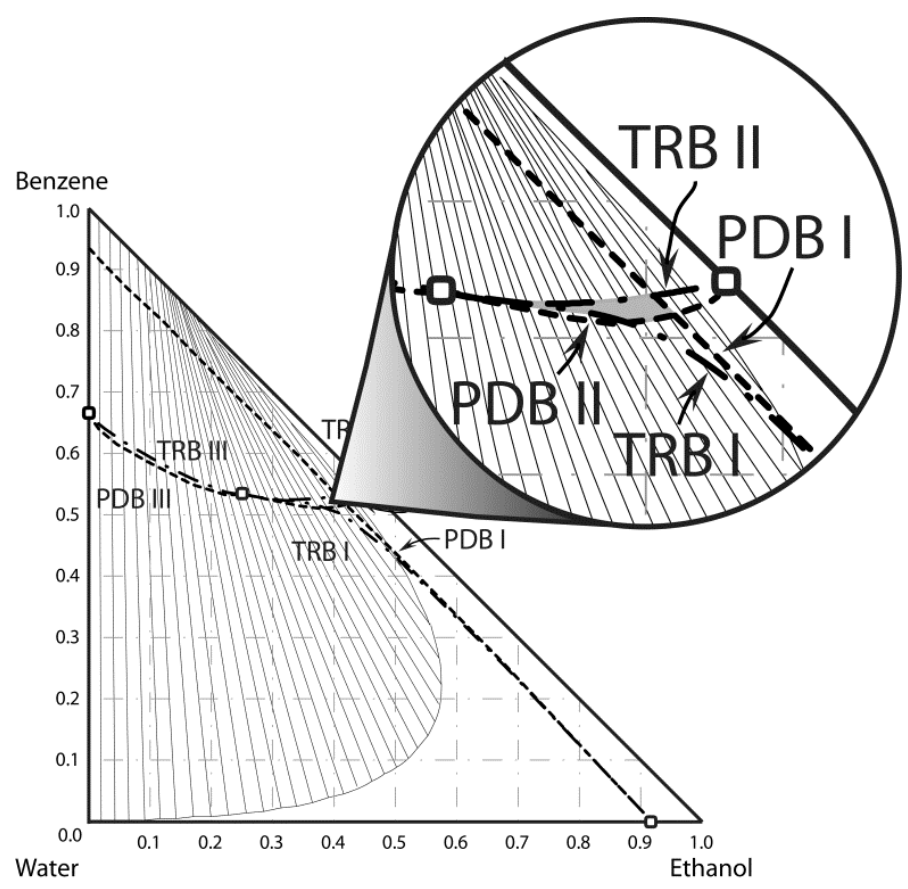

Fig. 5. Distillation region assigned by four distillation boundaries. $P D B$ II was exaggerated for the purpose of clarity only (in fact, it was very close to $T R B$ II)

Similar situation exhibited for the heterogeneous distillate $z_{\mathrm{D}}=(0.1269,0.5870,0.2861)$ situated on the convex side of TRB III, in region determined by TRB III and PDB III. This region was influenced by $P D B$ I. Once rectifying profile ran towards stable water node $(R=0.1)$, secondly for reflux ratio in range $R=0.2$ to $R=744$ rectifying composition profile approached to saddle azeotrope benzene water, while for $R=745$ the rectifying profile came up to stable node represented by pure benzene vertex. Accordingly, the distillate point was located in the common part of the distillation regions (Fig. 7)

Additionally, for distillate point $\boldsymbol{z}_{\mathbf{D}}=(0.3355,0.5231,0.1414)$ placed in heterogeneous region, it was observed, that critical values of reflux ratio shown on Fig. 7 were not the only critical values, for which rectifying profile might have ended in another distillation regions. For the reflux ratios $R=(0.5,0.8,1$, $4,7,8,14,22, \ldots, 77)$ distillation profiles approached the stable benzene node, while for values of $R=(0.4,0.9,2,6,7.7,9,19, \ldots, 78)$ they ran in the direction of vertex represented by water in the composition space (Fig. 8). For critical value of $R=81$ rectifying profile ended close to the ethanol 
vertex. Further increase of reflux ratio value resulted in jumping of distillation profile once towards to the benzene vertex, once to the ethanol vertex.

(a) Benzene

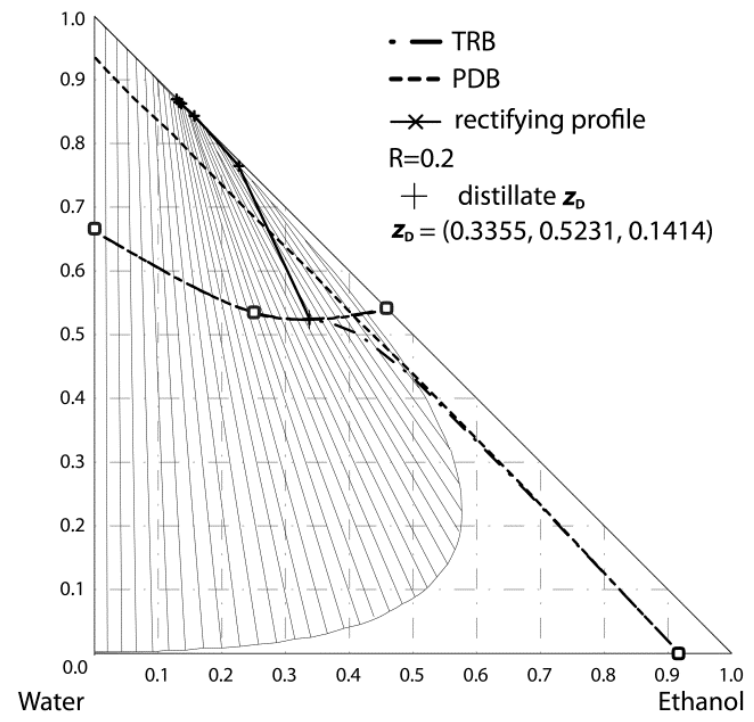

(b) Benzene

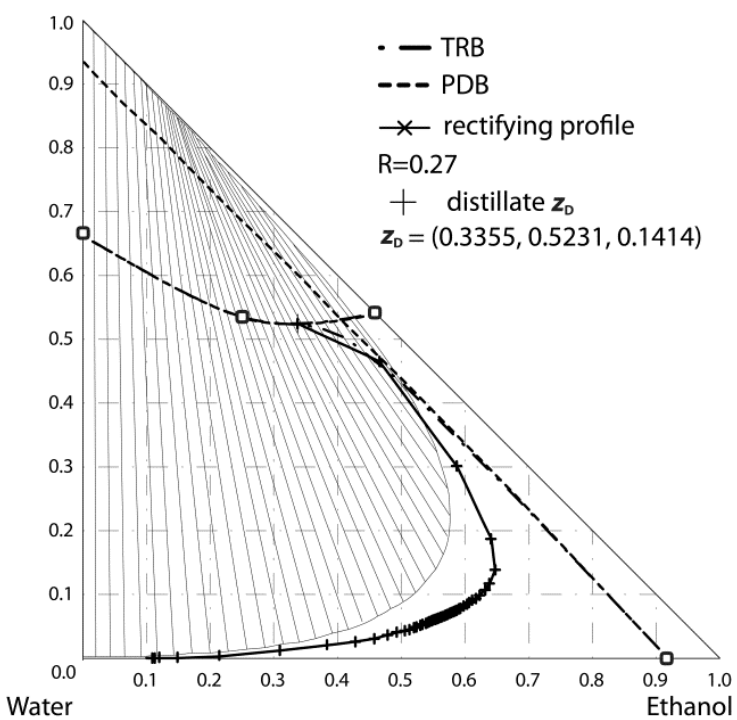

(c) Benzene

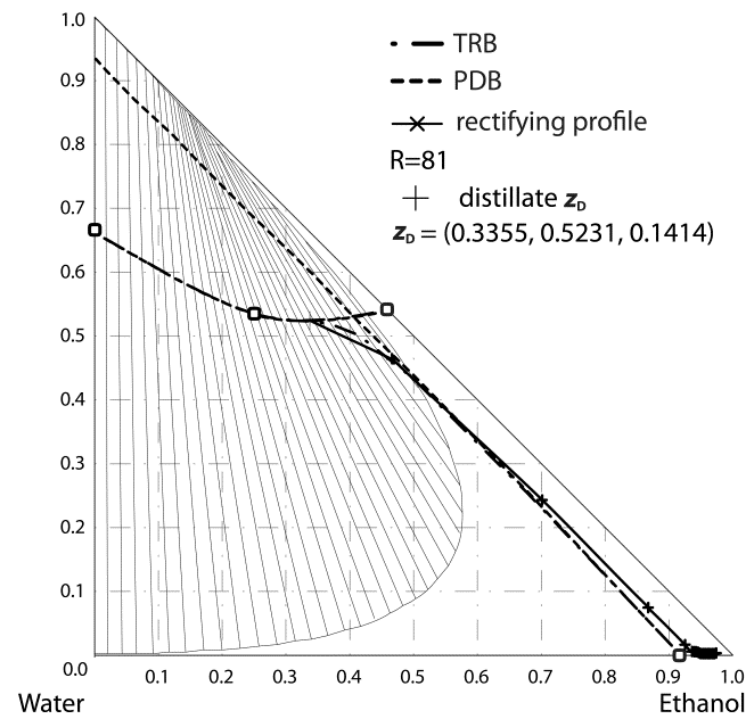

Fig. 6. Rectifying profiles for the distillate point located in the common area of two overlapped distillation regions; (a) $R=0.2$, (b) $R=0.27$ and (c) $R=81$

The second kind of interaction between different total reflux boundaries and pitchfork distillation boundaries occurred when region between $T R B$ and related $P D B$ was crossed by another total reflux boundary. This is the case, where occurred "cut-off effect" by the other total reflux boundary. For the heterogeneous mixture ethanol - benzene - water, rectifying profile should jump for all distillate composition points placed in whole region enclosed between TRB I and $P D B$ I boundaries (Fig. 9a, marked in light grey). Nevertheless, this region was cut by TRB II and parametrically sensitive area was bounded. As a rule, for distillate composition point to be found in this confined area (Fig. 9b, dark grey area) after changing the reflux ratio value, the rectifying profiles did not ended in different distillation regions. While the reflux ratio was being changed, rectification composition profile always aimed to the vertex represented by the benzene. 
(a) Benzene

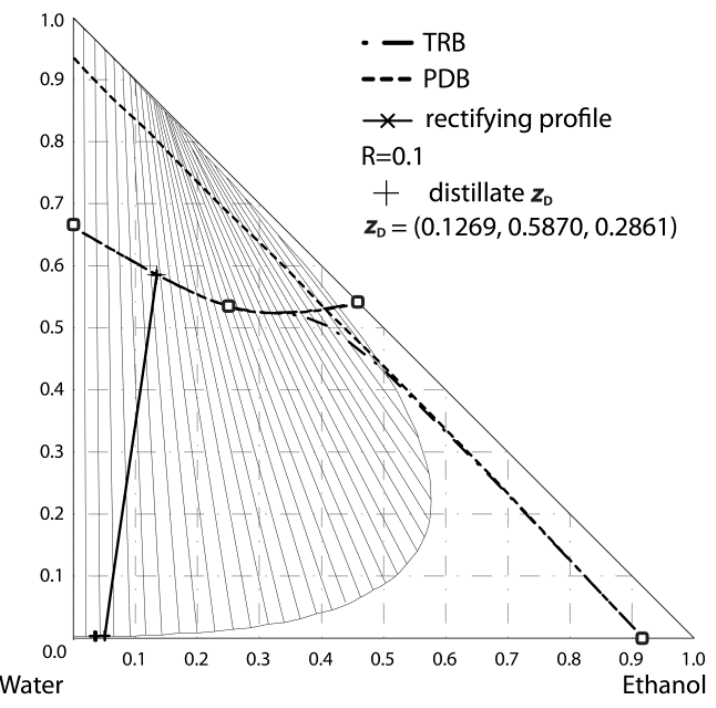

(c) Benzene

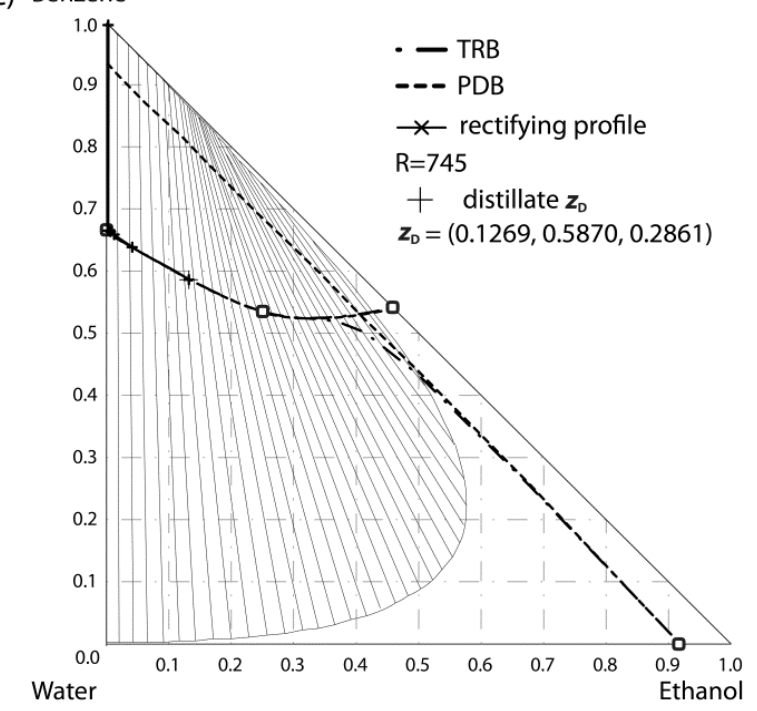

(b) Benzene

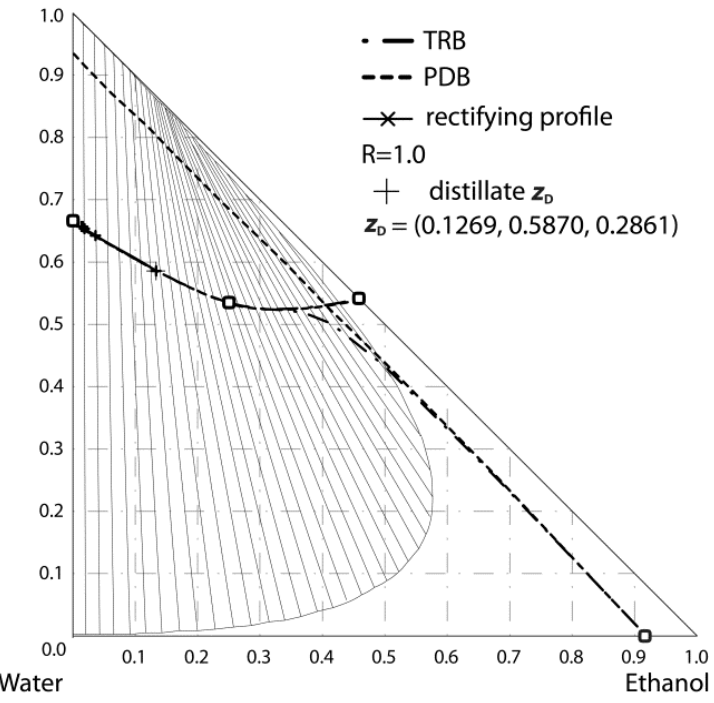

Fig. 7. Rectifying profiles for distillate $z_{D}=(0.1269,0.5870,0.2861)$; (a) $R=0.1$, (b) $R=1.0$ and (c) $R=745$

(a) Benzene

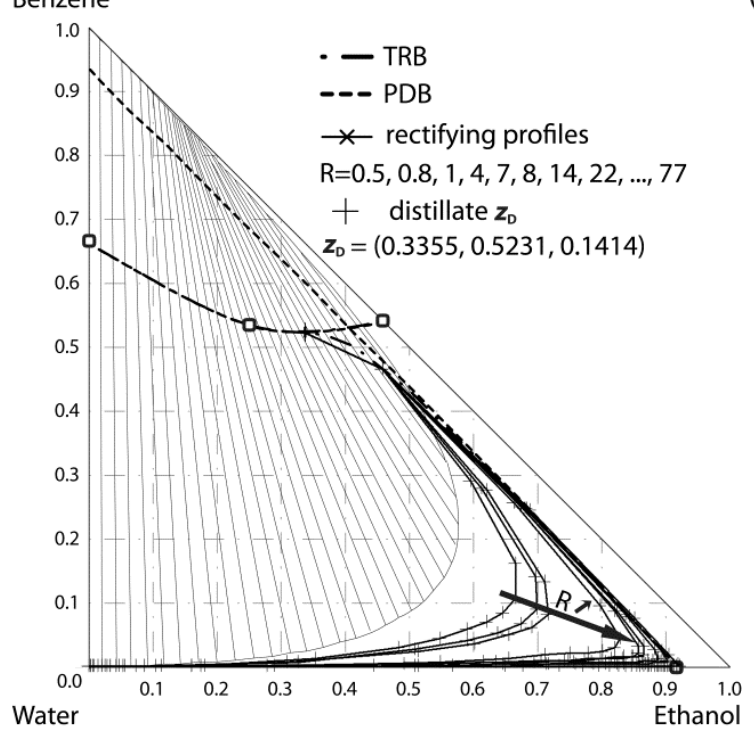

(b) Benzene

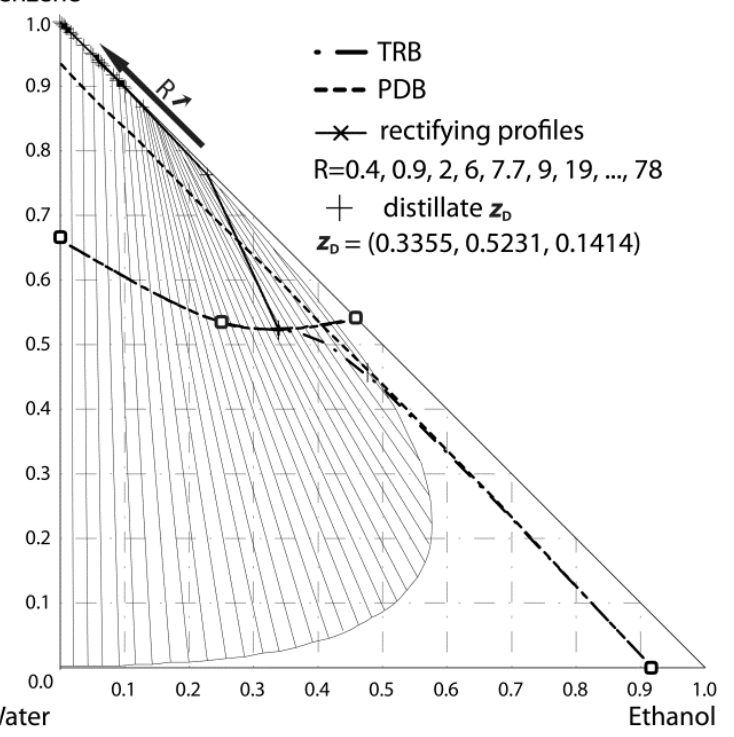

Fig. 8. Rectifying profiles for the distillate point located in the common area of two overlapped distillation regions; (a) $R=(0.5,0.8,1,4,7,8,14,22, \ldots, 77)$ and (b) $R=(0.4,0.9,2,6,7.7,9,19, \ldots, 78)$ 
(a) Benzene

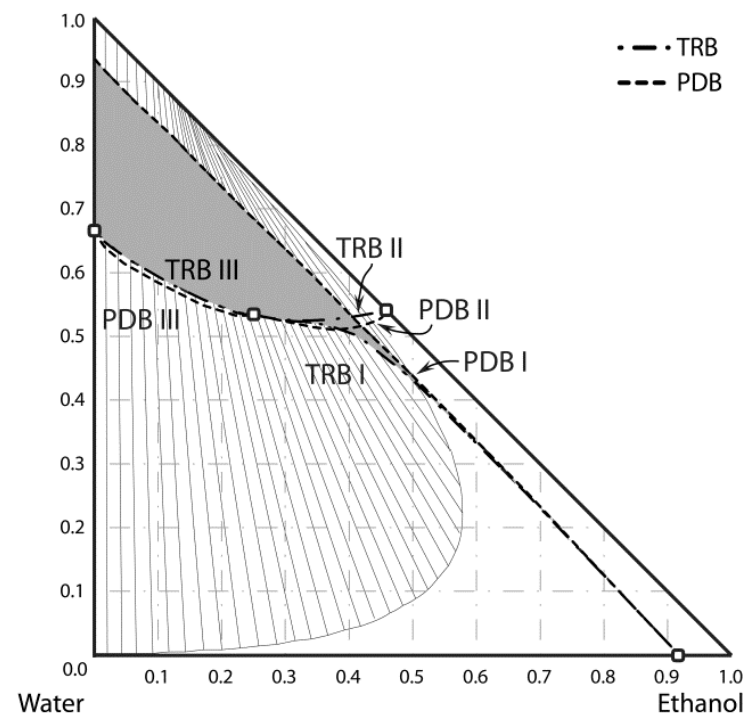

(b) Benzene

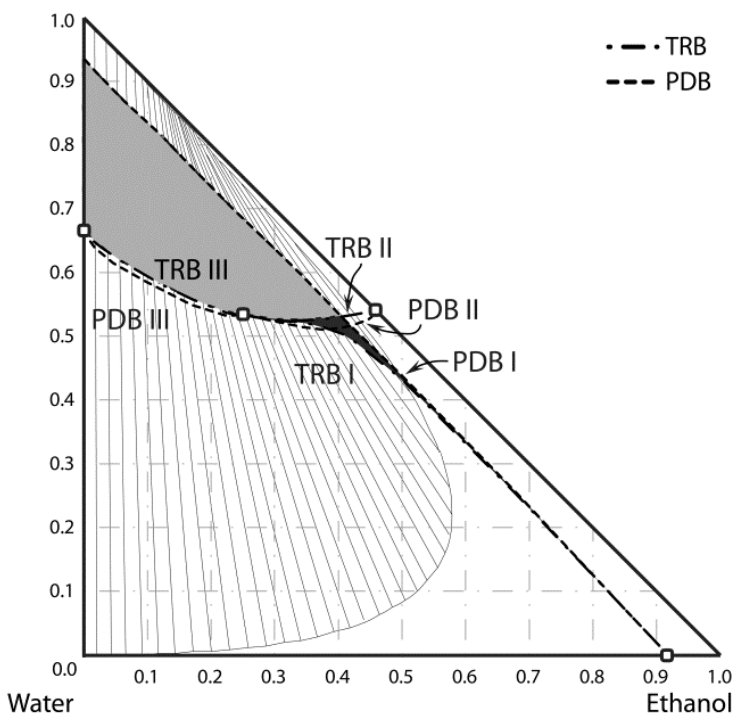

Fig. 9. Rectifying profiles for the distillate point located in the cut region ( $P D B$ II \& $P D B$ III have been exaggerated for the purpose of clarity only); (a) region enclosed between $T R B$ I and $P D B$ I boundaries and (b) confined area

\section{CONCLUSIONS}

Distillation is the most important separation technique. There is a significant industrial interest in the design and optimization of azeotropic distillation systems. In these cases, it is essential to keep in mind the critical convergence problems and possible infeasibilities, that can arise due mainly to the equilibrium restrictions, that are present in these complex systems. Residue curve maps are commonly used in developing separation flow schemes by checking the existence of distillation regions. Hardly anyone remembers that for staged columns there should be distillation line maps used. Residue curve maps are a valuable tool for packed column analysis. Pinch point curve maps apply in both cases. A distillation region is a composition subspace that contains the different residue curves (or distillation lines, or pinch point curves) with a common origin and end. Obviously, the existence, location, and curvature of distillation region boundaries are very important in the synthesis of azeotropic distillation sequences. Presented manuscript clarified how the existence of distillation boundaries influences the behavior of distillation profiles of staged distillation columns. It has been done by scrutinizing an overlapping of distillation regions in heteroazeotropic mixtures. To prove it, such composition points of the products (distillate points) were found for which the rectifying profiles were jumped into different distillation regions. Different distillation boundaries were assigned to the particular types of distillation column (staged or packed). For both types of columns, pitchfork distillation boundary existed. The area between related boundaries was parametrically sensitive. That confined area was representing the common part of two overlapped distillation regions. When a product was located in such area, the second product might have occurred in different distillation regions. When the product was located in the common area between regions assigned by two pairs of appropriate distillation boundaries, the second product might have occurred in three distillation regions. For a product located in the cut-off region, the second product occurred in the same distillation region. Described analysis is one of the elements that will allow quickly identifying possible to obtain products and feasible separations schemes. If it is combined with geometric designing methods, this analysis will facilitate and accelerate the design process reducing valuable time and resources. 
The author is grateful to his future wife - Ms. Dominika Wójtowicz, parents - Józefa and Andrzej Królikowscy for inspiring and motivating him to write this article. He also acknowledges Dr. Eng. Lechostaw Królikowski for the support and guidance he has been providing over the years.

\section{SYMBOLS}

$\begin{array}{ll}A_{i j}, A_{j i} & \text { parameters in NRTL Model, cal/mol } \\ A, B, C & \text { parameters in Antoine equation } \\ G_{i j}, G_{j i} & \text { binary parameters in NRTL Model } \\ \text { het } & \text { heterogeneous } \\ \text { hom } & \text { homogeneous } \\ n & \text { number of components } \\ p & \text { operating pressure, } \mathrm{kPa} \\ P D B & \text { pitchfork distillation boundary } \\ R & \text { gas constant, } 8.3144621 \mathrm{~J} /(\mathrm{K} \text { mol) } \\ R & \text { reflux ratio } \\ S D B & \text { simple distillation boundary } \\ {[\text { sa }]} & \text { saddle } \\ {[s n]} & \text { stable node } \\ T & \text { temperature, } \mathrm{K} \\ T R B & \text { total reflux boundary } \\ {[\text { un }]} & \text { unstable node } \\ x & \text { vector of mole fractions in liquid phase } \\ y & \text { vector of mole fractions in vapor phase } \\ z & \text { vector of mole fractions in (heterogeneous) product } \\ \text { Greek symbols } & \\ \alpha_{i j}, \alpha_{j i} & \text { parameter in NRTL Model } \\ \tau_{i j}, \tau_{j i} & \text { binary parameters in NRTL Model } \\ \xi & \text { nonlinear, dimensionless evaporating time } \\ \text { Subscripts } & \\ D & \text { distillate }\end{array}$

\section{REFERENCES}

Antoine C., 1888. Vapor pressures: new relationship between vapor pressure and temperature. Records of meetings of the Academy of Sciences, 107, 681-684, 778-780, 836-837 (in French).

Baur R., Krishna R., Taylor R., 2005. Influence of mass transfer in distillation: feasibility and design. AIChE J., 51, 854-866. DOI: 10.1002/aic.10328.

Bossen B.S., Bay Jargensen, S., Gani R., 1993. Simulation, design, and analysis of azeotropic distillation operations. Ind. Eng. Chem. Res., 32, 620-633. DOI: 10.1021/ie00016a008.

Brüggemann S., Marquardt W., 2011a. Conceptual design of distillation processes for mixtures with distillation boundaries. II. Optimization of recycle policies. AIChE J., 54, 1540-1556. DOI: 10.1002/aic.12377.

Brüggemann, S., Marquardt, W., 2011b. Conceptual design of distillation processes for mixtures with distillation boundaries: I. Computational assessment of split feasibility. AIChE J., 57, 1526-1539. DOI: 10.1002/aic. 12378.

Castillo F.J.L., Towler G.P., 1998. Influence of multicomponent mass transfer on homogeneous azeotropic distillation. Chem. Eng. Sci., 53, 963-976. DOI: 10.1016/s0009-2509(97)00418-1. 
Doherty M.F., Caldarola G.A., 1985. Design and synthesis of homogeneous azeotropic distillations. 3. The sequencing of columns for azeotropic and extractive distillations. Ind. Eng. Chem. Fundam., 24, 474-485. DOI: 10.1021/i100020a012.

Fidkowski Z.T., Doherty M.F., Malone M.F., 1993. Feasibility of separations for distillation of nonideal ternary mixtures. AIChE J., 39, 1303-1321. DOI: 10.1002/aic.690390806.

Gmehling J., Menke J., Krafczyk J., Fischer K., 2004. Azeotropic data. 2nd edition. 3 Vols. Wiley-VCH, Weinheim.

Gmehling J., Onken U., Arlt W., 1977. Vapor-liquid equilibrium data collection. DECHEMA Chem. Data Ser., Frankfurt.

Jobson M., Hildebrandt D., Glasser D., 1995. Attainable products for the vapour-liquid separation of homogeneous ternary mixtures. Chem. Eng. J. Biochem. Eng. J., 59, 51-70. DOI: 10.1016/0923-0467(95)030026.

Kiva V.N., Hilmen E.K., Skogestad S., 2003. Azeotropic phase equilibrium diagrams: A survey. Chem. Eng. Sci., 58, 1903-1953. DOI: 10.1016/s0009-2509(03)00018-6.

Królikowski A.R., Królikowski L.J., Wasylkiewicz S.K., 2007. Properties of distillation boundaries in ternary heterogeneous mixtures. XIX Polish Conference of Chemical and Process Engineering. Rzeszów, Poland, 3-7 September 2007, 87-90 (in Polish).

Królikowski A.R., Królikowski L.J., Wasylkiewicz S.K., 2011. Distillation profiles in ternary heterogeneous mixtures with distillation boundaries. Chem. Eng. Res. Des., 89, 879-893. DOI: 10.1016/j.cherd.2010.11.016.

Królikowski L.J., 1999. Selection of separation conditions of heteroazeotropes, In: SPR Reports, Report SPR 8/99. Institute of Chemical Engineering and Heating Equipment, Wrocław University of Technology, Poland, p. 22 (in Polish).

Królikowski L.J., 2001. Distillation boundaries created by the ternary azeotropes. Chem. Proc. Eng., 22, 807-812 (in Polish).

Królikowski L.J., 2002. Distillation regions for nonideal ternary mixtures. International Conference of Distillation and Absorption, Baden-Baden, Germany, 30 September-2 October 2002, Section 6-19.

Królikowski L.J., 2003. Determination of distillation regions for ternary azeotropic mixtures. IV $V^{\text {th }}$ Symposium on Distillation, Absorption and Extraction. Szklarska Poręba, Poland, 6-8 October 2003, 34-40 (in Polish).

Królikowski L.J., 2006. Determination of distillation regions for non-ideal ternary mixtures. AIChE J., 52, 532544. DOI: $10.1002 /$ aic. 10663.

Levy S.G., Van Dongen D.B., Doherty M.F., 1985. Design and synthesis of homogeneous azeotropic distillations. 2. Minimum reflux calculations for nonideal and azeotropic columns. Ind. Eng. Chem. Fundam., 24, 463-474. DOI: $10.1021 / \mathrm{i} 100020 \mathrm{a} 011$.

Lucia A., Taylor R., 2006. The geometry of separation boundaries: I. Basic theory and numerical support. AIChE J., 52, 582-594. DOI: 10.1002/aic.10668.

Lucia A., Taylor R., 2007. The geometry of separation boundaries. II. Mathematical formalism. AIChE J., 53, 1779-1788. DOI: 10.1002/aic.11204.

Mortaheb H.R., Kosuge H., 2004. Simulation and optimization of heterogeneous azeotropic distillation process with a rate-based model. Chem. Eng. Process., 43, 317-326. DOI: 10.1016/s0255-2701(03)00131-4.

Petlyuk F.B., Platonov V.M., Slavinskii D.M., 1965. Thermodynamically optimal method for separating multicomponent mixtures. Int. Chem. Eng., 5, 555-561.

Renon H., Prausnitz J.M., 1968. Local compositions in thermodynamic excess functions for liquid mixtures. AIChE J., 14, 135-144. DOI: 10.1002/aic.690140124.

Renon H., Prausnitz J.M., 1969. Estimation of parameters for the NRTL equation for excess Gibbs energies of strongly nonideal liquid mixtures. Ind. Eng. Chem. Process Des. Dev., 8, 413-419. DOI: 10.1021/i260031a019.

Rév E., 1992. Crossing of valleys, ridges, and simple boundaries by distillation in homogeneous ternary mixtures. Ind. Eng. Chem. Res., 31, 893-901.

Safrit B.T., Westerberg A.W., 1997. Algorithm for generating the distillation regions for azeotropic multicomponent mixtures. Ind. Eng. Chem. Res., 36, 1827-1840. DOI: 10.1021/ie960344r.

Serafimov L.A., 1970. The azeotropic rule and the classification of multicomponent mixtures VII. Diagrams for ternary mixtures. J. Phys. Chem. (USSR), 44, 567-642.

Shampine L.F., Reichelt M.W., 1997. The MATLAB ODE suite. SIAM J. Sci. Comput., 18, 1-22. DOI: $10.1137 /$ S1064827594276424. 
Springer P.A.M., van der Molen S., Krishna R., 2002. The need for using rigorous rate-based models for simulations of ternary azeotropic distillation. Comput. Chem. Eng., 26, 1265-1279. DOI: 10.1016/s00981354(02)00039-x.

Taylor R., Baur R., Krishna R., 2004. Influence of mass transfer in distillation: residue curves and total reflux. AIChE J., 50, 3134-3148. DOI: 10.1002/aic.10278.

Teixeira J.C., Sena Jr. F.C., Silva A.M.V., Stragevitch L., Silva J.M.F., 2009. Moving boundary in nonequilibrium simple batch distillation in non-ideal systems. Chem. Eng. Proc.: Process Intensification, 48, 15741578. DOI: 10.1016/j.cep.2009.10.013.

Van Dongen D.B., Doherty M.F., 1984. On the dynamics of distillation processes-V: the topology of the boiling temperature surface and its relation to azeotropic distillation. Chem. Eng. Sci., 39, 883-892. DOI: 10.1016/00092509(84)85057-5.

Wahnschafft O.M., Koehler J.W., Blass E., Westerberg A.W., 1992. The product composition regions of singlefeed azeotropic distillation columns. Ind. Eng. Chem. Res., 31, 2345-2362. DOI: 10.1021/ie00010a014.

Received 30 July 2011

Received in revised form 22 March 2012

Accepted 26 March 2012 